\title{
An Awesim Simulation Study: To Determine the Efficiency of Future Improvements on Tupras Izmit Oil Terminal
}

\author{
Özkan Uğurlu, Umut Yıldırım, Ercan Yüksekyıldız and Serdar Yıldız \\ Karadeniz Technical University, Maritime Transportation and Management Engineering Department, Sürmene-TRABZON,TURKEY
}

\begin{abstract}
Oil and oil products occupy an important place in the industry and transportation sectors, both as bunker and raw materials. Most oil and oil products are transported by sea. The aim of this study was to evaluate the handling capacity of the TuprasIzmit Tanker Terminal, which is an important hub for Turkey with regards to the transportation of oil and refined oil products. To assess the capacity of the port and to determine the amount of queuing that could form with regards to tug services; the Awesim simulation program was used. Based on the study results, a comparison was performed between the port's current annual handling capacity and the maximum amount of cargo it can handle. In addition, by using the study data, the maximum amount of queuing that can form in tug services was also calculated for days with unfavorable weather and sea conditions. This study thus represents a case study performed with the Awesim modeling program in order to determine port efficiency.
\end{abstract}

Key words: Port efficiency, Awesim, simulation.

\section{Introduction}

Simulation programs are useful and effective tools for analysis of projects requiring high investment costs, studies to improve the functioning of an existing system, and the analysis of the effectiveness and efficiency [1]. They do not require high investment cost and makes it possible to advanced planning and foresee problems that may occur about future.

The first requirement in the simulation system is designed a model by user. The model offers the key characteristics or behaviors/functions of the selected physical or abstract system or process to the user. Behavior of real system, the advantages and disadvantages could be predictable by the simulation model. Simulation is used in nearly every field such as engineering, scientific, and technological discipline. In the last decades, simulation systems have been adapted for a wide variety of applications. Today, the

Corresponding author: Özkan Uğurlu, Ph.D., assistant professor, research fields: maritime engineering sciences and ship's technology. E-mail: ozkanugurlu24@hotmail.com. techniques are employed in the design of new systems, the analysis of existing systems, training for all types of activities, and as a form of interactive entertainment [2].

Maritime industry, especially port establishment and management is an expensive type of business. Initial setup costs and operating costs are astronomic. Deficiencies or failures in the system can lead to high cost. Therefore simulation models have significance for port establishment and management. There are many studies about harbor location selection and efficient port management [3-7]. Many different methods can be used to determine if the port is managing efficient or not. Port efficiency can be variable from country to country and region to region [8]. It is possible to use many methods to determine efficiency such as: analytical modeling methods, multi-criteria decision-making methods, simulation modeling methods etc.

The most important part of modeling is to define the efficiency criteria because marine terminals are very complex and can be used for multipurpose. For 
instance, some ports which handling dry cargoes or general cargoes, efficiency criteria can be defined as amount of ships handled per day/week. On the other hand, the liquid cargo has much more value-added than the general cargo many vessels suffer demurrage and delays due to a lack of port facilities [9].Terminals which were established for handling valuable and dangerous oil products, efficiency criteria could be about safe and fast cargo handling. In any case the seaport should be modeled by analytical methods or simulation programs to check the port efficiency and handling capacity.

In this study Tupras Izmit Oil Terminal has been modeled by using Awesim Simulation (Awesim) program to test feasibility of the terminal, to check reliability of simulation models, to determine the weak points of operation process arising from geographic and technical limitations. In light of this information, determination of terminal intensity may occur in the future, and identify improvements which should be made. The TUPRAS Oil Terminal is one of the most important oil terminals in Turkey from both an economic and a strategic perspective.

\section{Literature Review}

Simulation modeling methods have been used for various purposes and wide range of industrial fields and topics since 1940/50s. Initially, Stainslaw Ulam was a Polish mathematician, he was led to consider a simulation approach for estimating the probability that a Canfield solitaire laid out with 52 cards will come out successfully in 1946. While computer programming languages begin to emerge, in the 1950s and early 1960s, R. W. Conway, B. M. Johnson, and W. L. Maxwell of Cornell University laid out the central problems of digital simulation in their papers. After 1980s simulation modeling showed great improvement and began to be used more intensively [10]. In the maritime industry, simulation technique has been generally used for modeling marine accidents, modeling ship construction processes, evaluating port operational efficiency, checking, etc.[11-15]. There are various studies about port modeling.

Bressman et al. (1978) utilized a technique for incorporating the uncertainty of certain key assumptions into the financial planning and evaluation of an investment proposal. Future annual cash inflows and outflows are simulated and used to evaluate a project in terms of overall financial feasibility. As a result of the study application of the technique to an actual Port Authority investment proposal representing a potential capital outlay of $\$ 400$ million [16].

Wichers (1988) made a numerical simulation model of a single point moored tanker to determine the effects of irregular waves, winds and currents. As a result of the study, the equation of motions of such model has been derived, and the rigid-body and mooring-line dynamics solved separately [17].

Carpenter and Ward (1990) developed a model which represents the overall operations of a marine terminal and includes the effect of traffic interactions. As a result it can provide assistance in the terminal planning process, if discrete event computer simulation model using [18].

Collier was approached to port as a system in his study. In the study port system components defined as; arrival or dispatch of cargo, the storage of goods under appropriate conditions, handling facilities of the port and the handling arrangements on ship. To operate these components efficiently some supportive facilities required, according to the study; engineering, labor, transportation and documentation procedures and resource allocation. As a result, port system analysis requires rigorous data collection methods and the subsequent building of specific models designed to test the effect of variations of the system parameters and demonstrates the principals involved in the construction of simulation models which allows the users to examine the effects of such factors as lorry queues, cargo inventory, maintenance policies, etc. [19].

Hassan (1993) defined the port as a complex system. 
According to the study, special care should be given when modeling a port. Also the paper presented an overview of a computer simulation program used as a management decision support tool helping in evaluating and improving the comprehensive port activities. A port simulation model has been proposed as a result of the study. The model could be used as a port management, decision supporter tool for analyzing, evaluating, and improving port performance capabilities [20].

Yun and Choi (1999) developed a simulation model of the container terminal system by using an object-oriented approach and object-oriented simulation software. They took a model like CTS (Pusan East Container Terminal) and analyzed the performance of the system from the result of the reduced model. Consequently, according to the study, the simulation model could be useful to determine the efficiency of the port and to determine required improvements [21].

Demirci (2003) investigated bottleneck points under overloading conditions by using simulation modeling method. As a result of this study the most critical bottleneck points were created by loading/unloading vehicles. An investment strategy was applied to the model at this point for load balancing of the port. Consequently, simulation was used to study improvements by adding resources within economic limitations [22].

Yeo et al. (2007) used Awesim simulation modeling in order to forecast the traffic density at the port of Busan that occured in 2011. In the study, 10 years (1993-2002) of Busan harbor data were used. As a result they mentioned, the necessity of reallocation of terminal functions in number two pier, enlarging the superstructure of the container terminals, and the cancellation of one of the existing anchorage area [23].

Uğurlu et al. (2014) modeled BOTAS Ceyhan Marine Terminal by using Awesim simulation program. In this study terminal capacity, terminal congestion, loading times, maneuvering time, types of ships arriving to port and transportation capacity of BOTAS Ceyhan Marine Terminal has been examined. According to study results, Awesim simulation model can be used easily for optimizing of port operation in container, bulk and liquid cargo terminals [1].

Simulation method is using in many fields such as modeling maritime traffic [24, 25], planning of a terminal $[9,26,27]$, modeling of a port $[28,29]$ and to measure the performance [30, 31].

Different from other studies in the literature, this study forecasted the port efficiency of Tupras Izmit Oil Terminal and traffic congestion that may occur in the future. In addition, put forth the possible effects of a new dock, on the port efficiency and traffic congestion. This study is an example for the estimation of traffic density in the liquid cargo terminals and terminal planning studies.

\section{Awesim Simulation}

SLAM II is a general-purpose language which has been used since 1979 to model a wide variety of systems such as manufacturing, transportation, communication systems, information systems, military operations, health care and banking [32, 33]. Awesim is a general purpose simulation tool which replaced the SLAM system software in 1996. Awesim incorporates the Visual SLAM modeling methodology, which is a new simulator based on the powerful and proven modeling concepts used in the SLAM II modeling language. The basic component of a Visual SLAM model is a network or flow diagram, which graphically portrays the flow of entities (people, parts or information, for example) through the system [34]. An Awesim project consists of one or more scenarios, each of which represents a particular system alternative. A scenario contains component parts. Awesim incorporates the Visual SLAM modeling methodology. The basic component of a Visual SLAM model is a network, or flow diagram, which graphically portrays the flow of entities (people, parts or information, for example) through the system. A Visual SLAM network 
is made up of "nodes" at which processing is performed, connected by "activities" which define the routing of entities and the time required to perform operations [35].

Awesim can support a wide range of tasks which are necessary for a simulation project. Awesim also provides integrating capabilities to store, retrieve, browse and communicate with externally written software applications. The most fundamental feature of the Awesim architecture is its openness and interconnectivity to databases, spreadsheets and word processing programs such as Microsoft Office. Awesim is built in Visual Basic and $\mathrm{C} / \mathrm{C}++$ and programs written in these languages are easily incorporated into its architecture. The details on the capabilities of Awesim are contained in the Awesim User's Guide [35]. Variety of conditions and situations can be simulated by Awesim, such as different weather conditions, port's inbound or outbound traffic congestion, cargo operations etc. In this study, Awesim simulation program was used to modeling the Tupras Izmit Tanker Terminal.

\section{Tuprasizmit Tanker Terminal}

Tupras Izmit Tanker Terminal is placed in the area of Korfez Country in Izmit. The terminal services the tanker vessels carrying oil and its derivatives.

GPS position of the terminal is approximately $40^{\circ} 44^{\prime} 43.0^{\prime \prime} \mathrm{N}-29^{\circ} 46^{\prime} 04.8^{\prime \prime} \mathrm{E}$. There is one crude oil platform able to handle maximum 300,000 deadweight (DWT) and two jetties able to handle maximum 100,000 DWT. As shown in Figure 1 there are totally 8 quays, including the platform. Table 1 includes descriptive information about Quays.

However, due to the storage limits of the terminal, quay length restriction and water depth of the area, large tonnage ships cannot berth to the harbor. The terminal serves every day of the year [36].

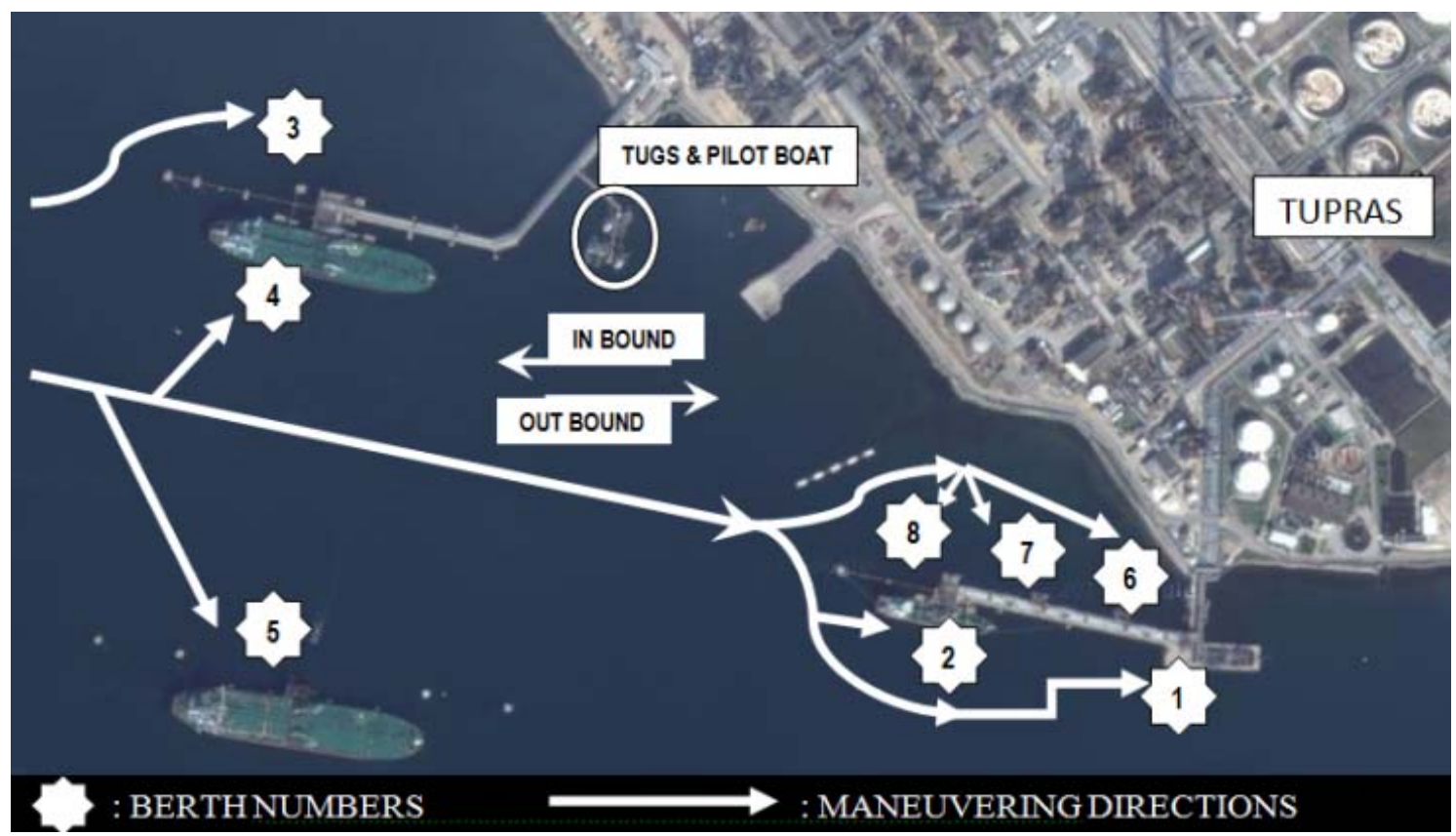

Fig. 1 TuprasIzmit Terminal.

Table 1 Terminal properties.

\begin{tabular}{lll}
\hline Name of the quay & Hose connection & Average rate \\
\hline Quay 1- Quay 2 & $8 \times 10 ”$ & $500-750 \mathrm{~m}$. tons/hours \\
Quay 3- Quay 4 & $20 \times 6 "$ up to 24” & $2,500 \mathrm{~m}$. tons $/$ hours \\
Quay 5 & $4 \times 16 "$ & $5,000-8,000 \mathrm{~m}$. tons/hours \\
\hline
\end{tabular}




\section{Application of Awesim Simulation}

In this study Awesim Simulation's Network Model was used to modeling TUPRAS Izmit Oil Terminal. TUPRAS Oil Terminal is one of the most important oil terminals in Turkey. A large portion of refined petroleum products on the domestic market, and in particular a significant portion of the processed product needs of the Istanbul region is meeting from this terminal. Istanbul is the heart of Turkey and one of the significant trade centers of the world. Day by day, Istanbul's processed product need is increasing. Large amount of oil product needs are met by the oil terminals, which is located in Ambarli, European side. Draft restriction is the most important disadvantage of the terminals located there; terminals are not suitable for berthing of vessels on the 10,000 DWT. Therefore, refined petroleum products needs of the region could be provided from only Tupras Marine Terminal quays No. 1 and No. 2 (Figure 1). Because, Tupras Terminal quays suitable for berthing and cargo operations of large tonnage vessels.

Day by day, processed oil product requirement will increase around oil product shipment areas; including Istanbul and the surrounding areas. As a consequence, the number of incoming ships to Tupras Oil Terminal will increase. In this study, actual terminal condition and predicted terminal congestion was modeled, by using Awesim Simulation. Then the developed models were compared. This study is a case study of Awesim Simulation model. As shown in Figure 1, there are 8 berths at this terminal. This simulation study comprised of 3 different scenarios, and evaluated by running for 8,670 hours which means 365 day. It was assumed that, vessels come to the terminal between 8-12 and 6-10 hour periods. Duration of stay in the port varies according to vessel length, ballast capacity, loading rate of the terminal, and paper workload before and after the operations. In this study, the duration of stay in the berth was built up according to the timetable of previous ship moored to the berth. The frequency of arrival at the port of ships has been determined according to data obtained from Marine Traffic for 15 daily periods [37, 38]. Table 2 gives explanatory information about tonnage of the incoming vessels, duration of stay at port, and frequency of visits.

Pilotage and tug facilities are compulsory for berthing and departure maneuvers. Berth No. 6-7-8 are especially for bunker barges. There is no pilotage and tug obligation for barges' berthing and departure maneuvers. Therefore, berth No. 6-7-8 were excluded in this study. For the other berths, it is not possible to provide tug and pilotage facilities before completion of current maneuvers. Duration of berthing and departure maneuvers calculated and the average duration were applied as an hour. Pilotage and tug services are not provided in heavy weather conditions. According to weather reports, the number of stormy weathers at Tupras Marine Terminal was determined as 30 days per year. These 30 days were distributed evenly in created scenarios. The following findings tried to be obtained:

- The maximum number of vessels berthing to the terminal for 1 year period (for each year);

- The maximum queue and waiting time for pilotage services;

- The maximum queue and waiting time for quays and platform;

- Efficiency of berths at the terminal;

- Additional 1 quay was modeled, in order to determine the queue changes of berth $\mathrm{Nr} 1$ and $\mathrm{Nr} 2$.

Table 2 Berth query information.

\begin{tabular}{llll}
\hline Berth Nr. & Tonnage of vessels able to berth & Vessel's duration of stay at port & Average frequency of visits \\
\hline $1-2$ & $1,000-10,000$ DWT & $16-20$ hours & $60 \%(30 \%-30 \%)$ \\
$3-4$ & $10000-100000$ DWT & $20-24$ hours & $30 \%(15 \%-15 \%)$ \\
5 & $100000-300000$ DWT & $24-28$ hours & $10 \%$ \\
\hline
\end{tabular}




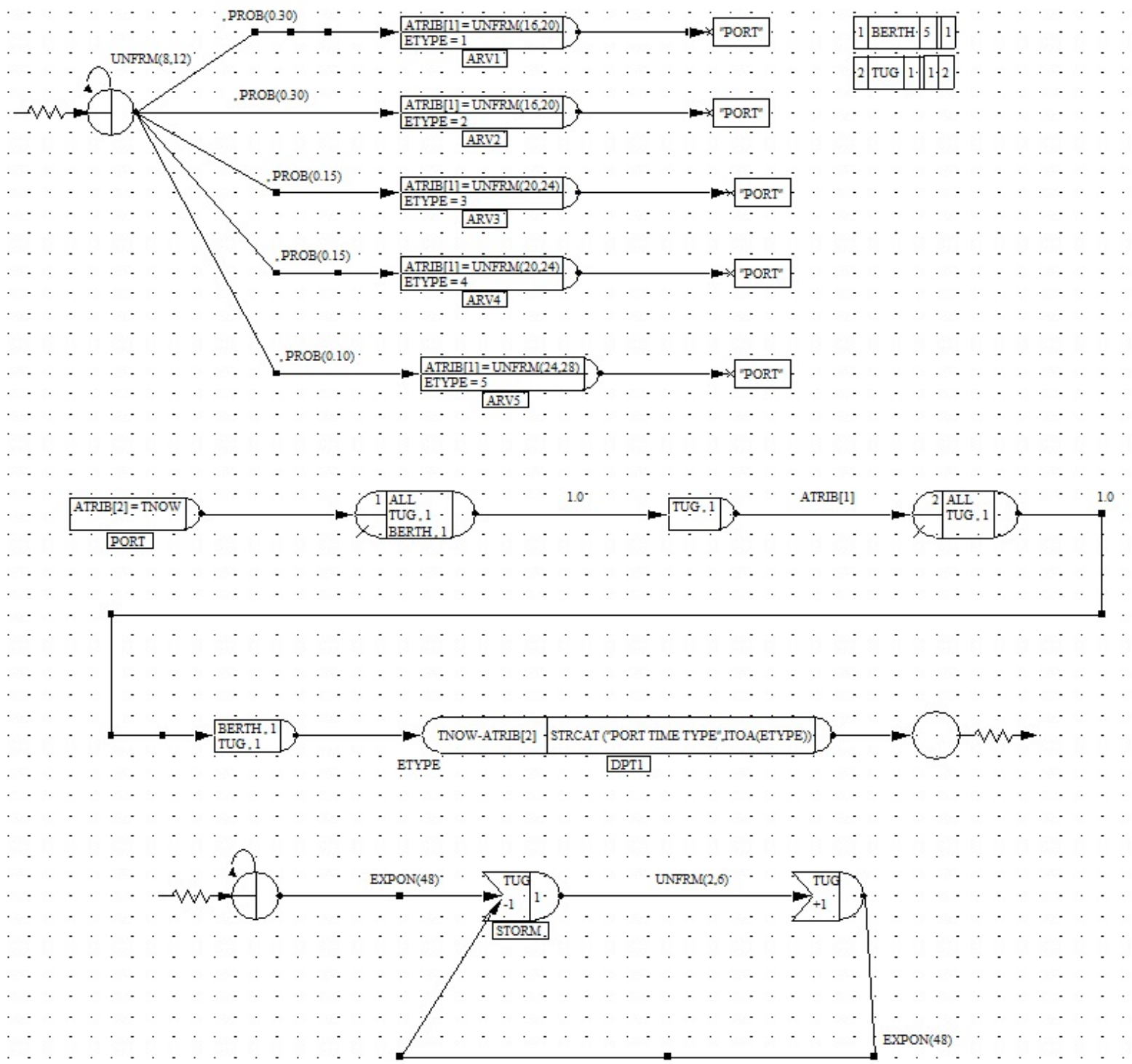

Fig. 2 TuprasIzmit Marine Terminal scenario 1 simulation flowchart (12-24 hours).

\subsection{Scenario 1}

In Scenario 1, actual condition of the TuprasIzmit Marine Terminal was simulated. Vessel arrival frequency was simulated to be between 8 and 12 hours (Figure 2).

According to the Simulation outcomes; 253 vessels to quay No. 1, 273 vessels to quay No. 2, 140 vessels to quay No. 3, 133 vessels to quay No. 4 and 75 vessels to platform (quay No. 5) have been arrived for a yearly period, totally 874 vessels observed. Incoming vessels were waiting for 15 minutes before berthing due to vessel traffic. Average queue quantity of five berths has been determined as 2 . Terminal tug services could be available after 15 minutes of the vessel's arrival. So 1 queue is comprised and vessels have to wait for 15 minutes for tug service. Preoccupation of the tug is $20 \%$ of the total. That has been observed in the heavy weather conditions, maximum queue quantity may rise up to 7 and vessel operations may be delayed about 11.6 hours (Table 3 ).

\subsection{Scenario 2}

In Scenario 2, vessel arrival frequency was simulated to be between 6 and 10 hours (Figure 3 ). The terminal congestion, which will occur after the possible 
Table 3 Yarimca TUPRAS Marine Terminal Scenario 1 simulation outputs (8-12 hours).

\begin{tabular}{|c|c|c|c|c|c|}
\hline \multicolumn{6}{|c|}{ Statistics for vessels based on observation } \\
\hline Quay number & $\begin{array}{l}\text { Mean value } \\
\text { (hours) }\end{array}$ & $\begin{array}{l}\text { Standard } \\
\text { deviation } \\
\text { (hours) }\end{array}$ & $\begin{array}{l}\text { Number of } \\
\text { observations } \\
\text { (Pcs) }\end{array}$ & $\begin{array}{l}\text { Minimum } \\
\text { value } \\
\text { (hours) }\end{array}$ & $\begin{array}{l}\text { Maximum } \\
\text { value } \\
\text { (hours) }\end{array}$ \\
\hline Quay 1 & 20.574 & 1.668 & 253 & 18.033 & 27.578 \\
\hline Quay 2 & 20.494 & 1.658 & 273 & 18.039 & 26.926 \\
\hline Quay 3 & 24.421 & 1.544 & 140 & 22.035 & 30.587 \\
\hline Quay 4 & 24.399 & 1.441 & 133 & 22.153 & 28.99 \\
\hline Quay 5 & 28.680 & 1.750 & 75 & 26.189 & 37.542 \\
\hline \multicolumn{6}{|l|}{ File Statistics } \\
\hline File Number & Label/Type & $\begin{array}{l}\text { Average length } \\
\text { (pcs) }\end{array}$ & $\begin{array}{l}\text { Standard deviation } \\
\text { (pcs) }\end{array}$ & $\begin{array}{l}\text { Maximum queue } \\
\text { (pcs) }\end{array}$ & $\begin{array}{l}\text { Average waiting time } \\
\text { (hours) }\end{array}$ \\
\hline 1 & Quay & 0.024 & 0.154 & 1 & 0.243 \\
\hline 2 & Tugboat & 0.025 & 0.158 & 2 & 0.254 \\
\hline 3 & Weather conditions & 5.193 & 0.518 & 7 & 11.658 \\
\hline \multicolumn{6}{|l|}{ Resource statistics } \\
\hline Resource number & Resource label & $\begin{array}{l}\text { Average utilization } \\
\text { (pcs) }\end{array}$ & $\begin{array}{l}\text { Standard deviation } \\
\text { (pcs) }\end{array}$ & $\begin{array}{l}\text { Current utilization } \\
\text { (pcs) }\end{array}$ & $\begin{array}{l}\text { Maximum utilization } \\
\text { (pcs) }\end{array}$ \\
\hline 1 & Quay & 2.218 & 0.519 & 2 & 5 \\
\hline 2 & Tugboat & 0.200 & 0.400 & 1 & 1 \\
\hline Resource number & Current available & Average available & $\begin{array}{l}\text { Minimum } \\
\text { available }\end{array}$ & & $\begin{array}{l}\text { Maximum } \\
\text { available }\end{array}$ \\
\hline 1 & 5 & 2.782 & 1 & & 5 \\
\hline 2 & 1 & 0.712 & -1 & & 1 \\
\hline
\end{tabular}

future increase in demand of the processed oil products, has been presented.

According to the Simulation outcomes, 334 vessels to quay No. 1, 328 vessels to quay No. 2, 196 vessels to quay No. 3, 164 vessels to quay No. 4 and 101 vessels to platform (quay No. 5) have been arrived for a yearly period, totally 1,096 vessels observed. As a result of the arrangement of vessel arrival frequency as 6-10 hours instead of 8-12 hours, the increase in the amount of ships arriving at the port has been observed approximately $25 \%$. Incoming vessels were waiting for 15 minutes before berthing due to vessel traffic. Average queue quantity of five berths has been determined as 1. Terminal tug services could be available after 20 minutes of the vessel's arrival because of the terminal congestion. So 3 queues are comprised and vessels have to wait for 20 minutes for tug service. Preoccupation of the tug is $66.3 \%$ of the total. That has been observed in the heavy weather conditions, maximum queue quantity may rise up to 8 but there were not too much delay at vessel operations.

\subsection{Scenario 3}

In Scenario 3, the answer to that question was sought; if a new quay was built, how will that affect the terminal operations? The new quay has been modeled to have the same characteristics with quays No. 1 and No. 2, where vessels use most often. According to the 3rd scenario results, the new quay will be reduced the workload of berth Nr.1 and Nr.2. Without a change in total vessel traffic, load of the berth No.1 and No.2 would be reduced by $21 \%$. The main reason of the lack of change in the total number of vessels, the frequency of arrival of the ship was kept constant and $60 \%$ of initial workload was shared equally between 3 quays (berth Nr.1, Nr.2 and new quay).

\section{Results}

In this simulation study, has been demonstrated the queue density of drift area, port entrance and anchorage area according to the current inbound and outbound vessel traffic frequency with the variable weather 
conditions. In addition, dock densities, towage and pilotage congestion were indicated, which will occur in case of the increase in vessel density, or to build a new port berths in order to increase port efficiency. Uğurlu et al. (2014) have made a similar Awesim Modeling study on the BOTAŞ Ceyhan Oil Terminal. In the study, the frequency of arrival of vessels; 12-24 hours, 12-36 hours, 24-36 hours and 24-48 hours as modeled in four different scenario. As a result of the study, Awesim simulation methods' availability has been revealed in the harbor modeling studies [1]. In this study, any development planned in the port made with Awesim simulation modeling program, run for one yearly period and demonstrated how it will affect the port efficiency. It has been indicated that newly constructed dock reduce the burden of other docks approximately 0.20 percent.

\section{Conclusions}

Constantly increasing world population, the need for raw materials and export goods demonstrates the importance of maritime trade will continue to increase. In particular, due to the effectiveness of low cost transportation of voluminous cargoes, worldwide logistics companies tend to marine transportation Therefore maritime traffic is constantly increasing in ports and open seas. The solution of this problem is to build new ports or to increase the capacity of existing ports. The study revealed the situation of TuprasIzmit Terminal which may occur when the frequency of arrival of a tanker ships increased. If it was possible to achieve much more information about the port, more comprehensive modeling study could be done. The results of the study cannot be considered completely accurate. This study is a case study of Awesim modeling program and gives preliminary information about the workability and handling capacity of the port. If there was clearer information about the frequency of incoming vessels, cargo waiting time, port exceptions, meteorological conditions and other values that affect the handled vessel's count, much more realistic results could be obtained. Port development projects require huge financial resource, so the phases of the project can be modeled on the program in order to evaluate the advantages and disadvantages Simulation Models especially provide great benefits in terms of observing the financial risks may occur in the future. This study has revealed Awesim simulation program that can be used for this purpose. In addition, Awesim Simulation modeling program could be used in many areas such as, port efficiency in the maritime sector, capacity analysis and risk analysis.

\section{References}

[1] Uğurlu, Ö., Yüksekyıldız, E., and Köse, E. 2014. "Simulation Model on Determining of Port Capacity and Queue Size: A Case Study for BOTAS Ceyhan Marine Terminal."'TransNav, the International Journal on Marine Navigation and Safety of Sea Transportation 8(1): 143-50.

[2] Smith, R. D. and M. Chief Scientist. 1999. Simulation: The Engine behind the Virtual World. GEN 1: 72.

[3] Chang, Y. T., Lee, S. Y., and Tongzon, J. L. 2008. "Port Selection Factors by Shipping Lines: Different Perspectives between Trunk Liners and Feeder Service Providers."Marine Policy 32(6): 877-85.

[4] Chou, C. C. 2007. "A fuzzy MCDM Method for Solving Marine Transshipment Container Port Selection Problems."Applied Mathematics and Computation 186(1): 435-44.

[5] Lirn, T., Thanopoulou, H., Beynon, M. J., and Beresford, A. K. C. 2004. "An Application of AHP on Transhipment Port Selection: A Global Perspective."Maritime Economics \& Logistics 6(1): 70-91.

[6] Ramani, K. V. 1996. “An Interactive Simulation Model for the Logistics Planning of Container Operations in Seaports."SIMULATION 66(5): 291-300.

[7] Slack, B. 1985. "Containerization, Inter-Port Competition, and Port Selection."Maritime Policy and Management 12(4): 293-303.

[8] Clark, X., Dollar, D., and Micco, A. 2004. "Port Efficiency, Maritime Transport Costs, and Bilateral Trade." Journal of Development Economics 75(2): 417-50.

[9] Kang, D. K., Kyu-Seok Kwak, K. S., and Nam, K. C.2014. "Study on Vitalizing Port Operation at Ulsan Port: Focused on Main Port of Ulsan."Journal of Shipping and Ocean Engineering(4): 72-8.

[10] Goldsman, D., Nance, R. E., and Wilson, J. R. 2010. “A Brief History of Simulation Revisited."Proceedings of the Winter Simulation Conference. Winter Simulation Conference: 567-74. 


\section{An Awesim Simulation Study; To Determine the Efficiency of Future Improvements on TuprasIzmit Oil Terminal}

[11] Goerlandt, F., and Kujala, P. 2011. "Traffic Simulation Based Ship Collision Probability Modeling."Reliability Engineering \& System Safety 96(1): 91-107.

[12] Hirsch, B. E., Kuhlmann, T., and Schumacher, J. 1998. "Logistics simulation of recycling networks."Computers in Industry 36(1): 31-8.

[13] Kim, H., Park, J.H., Lee, D., and Yang, Y. S. 2004. "Establishing the Methodologies for Human Evacuation Simulation in Marine Accidents."Computers \& Industrial Engineering 46(4): 725-40.

[14] Lee, T.W., Park, N.K., and Lee, D.W. 2003. "A Simulation Study for the Logistics Planning of a Container Terminal in View of SCM."Maritime Policy \& Management 30(3): 243-54.

[15] Uğurlu, Ö., Köse, E., Yıldırım, U., and Yüksekyıldız, E. 2015. "Marine Accident Analysis for Collision and Grounding in Oil Tanker Using FTA Method."Maritime Policy \& Management 42(2): 163-85.

[16] Bressman, L. H., Browne, J. J., Nanninga, C. L., and Weintrob, B. 1978. "Financial Simulation Model: Assessing Project Risk at the Port Authority of New York and New Jersey."Proceedings of the 10th conference on Winter simulation(2): 955-61.

[17] Wichers, J. E. W. 1988. "A Simulation Model for a Single Point Moored Tanker." Technische Universiteit Delft.

[18] Carpenter, B. C., and Ward, T. 1990. "The Use of Computer Simulation for Marine Terminal Planning.". Simulation Conference Proceedings: 802-4

[19] Collier, P. 1980. "Simulation as an Aid to the Study of a Port as a System."Ship Operation Automation(3): 51-6.

[20] Hassan, S. A. 1993. Port activity simulation: an overview. ACM SIGSIM Simulation Digest 23(2): 17-36.

[21] Yun, W. Y., and Choi, Y. S. 1999. "A Simulation Model for Container-Terminal Operation Analysis Using an Object-Oriented Approach."International Journal of Production Economics 59(1): 221-30.

[22] Demirci, E. 2003. "Simulation Modelling and Analysis of a Port Investment."Simulation 79(2): 94-105.

[23] Yeo, G.T., Roe, M., and Soak, S.M. 2007. "Evaluation of the Marine Traffic Congestion of North Harbor in BusanPort."Journal of Waterway, Port, Coastal, and Ocean Engineering 133(2): 87-93.

[24] Köse, E., Başar, E., Demirci, E., Güneroğlu, A., and
Erkebay, Ş. 2003. "Simulation of Marine Traffic in Istanbul Strait."Simulation Modelling Practice and Theory 11(7): 597-608.

[25] Azadeh, M. A., Shoja, B. M., Kazemian, P., and Hojati. Z. T.,2013. "A Hybrid Ant Colony-Computer Simulation Approach for Optimum Planning and Control of Maritime Traffic."International Journal of Industrial and Systems Engineering 15(1): 69-89.

[26] Park, N.K., and Dragović. B. 2009. "A Study of Container Terminal Planning.”FME transactions 37(4): 203-9.

[27] Huang, W.C., Kuo, T.C., and Wu, S.C. 2007. "A Comparison of Analytical Methods and Simulation for Container Terminal Planning." Journal of the Chinese Institute of Industrial Engineers 24(3): 200-9.

[28] Ragheb, M. A. S., Rekab, K., and Tadj, L. 2010. Validating a Port Simulation Model with Application to the Port of Alexandria, Egypt.'International Journal of Simulation and Process Modelling 6(2): 115-25.

[29] Guan, Y., and Yang, K. H. 2010. "Analysis of Berth Allocation and Inspection Operations in a Container Terminal."Maritime Economics\&Logistics 12(4): 347-69.

[30] Dragović, B., Park, N. K., Radmilović, Z., and Maraš. V.2005. "Simulation Modelling of Ship-Berth Link with Priority Service."Maritime Economics \& Logistics 7(4): 316-35.

[31] Nam, K.C., Kwak, K.S., and Yu. M. S., 2002. "Simulation Study of Container Terminal Performance."Journal of Waterway, Port, Coastal, and Ocean Engineering 128(3): 126-32.

[32] Maria, A. 1997. "Introduction to Modeling and Simulation."Proceedings of the 29th conference on Winter simulation. IEEE Computer Society: 7-13.

[33] O'Reilly, J. 1994. "Introduction to SLAM II and SLAMSYSTEM."Simulation Conference Proceedings: 415-19.

[34] Pritsker, A. A. B., and J. J. O'Reilly. 1998. “AweSim: the Integrated Simulation System."Simulation Conference Proceedings: 249-55.

[35] O'Reilly, J. J., and Lilegdon, W. R. 1999. "Introduction to AweSim."Simulation Conference Proceedings: 196-200

[36] Governorship, K. 2011. Gulf of Izmit Port Area Report Kocaeli.

[37] URL1. 2015. Marine Traffic.

[38] URL2. 2015. Kocaeli Port Authority. 